Cell Research (2002); 12(1):63-68

http://www.cell-research.com

\title{
The molecular characterization of maize B chromosome specific AFLPs
}

\author{
Zhong Xia QI, Hui ZENG, Xiu Lan LI, Cheng Bin CHEN, Wen QiN SONG, Rui Yang CHEN* \\ The College of Life Sciences, Nankai University, Tianjin 300071, China
}

\begin{abstract}
The origin and evolution of B chromosomes could be explained by the specific DNA sequence on them. But the specific sequences known were quite limited. To investigate maize B chromosome sqicific DNA sequeces, maize genomes with and without B chromosomes were analyzed by AFLP. Only 5 markers were found specific to genomes with B chromosomes among about 2000 AFLP markers. Southern hybridization and sequence analysis revealed that only the sequence of M8-2D was a B chromosome specific sequence. This sequence contained the telomeric repeat unit AGGGTTT conserved in plant chromosome telomeres. In addition, the sequence of M8-2D shared low homology to clones from maize chromosome 4 centromere as well. M8-2D were localized to B chromosome centromeric and telomeric regions.
\end{abstract}

Key words: Maize, B chromosome, AFLP, FISH.

\section{INTRODUCTION}

B chromosomes (Bs) are also called supernumerary chromosomes, accessory chromosomes or extra chromosomes. They are supernumerary to the standard chromosome (A chromosomes) set, which are found in hundreds of plants and animals. They are often morphologically distinct from A chromosomes, being smaller and more highly heterochromatic in most cases. B chromosomes are inherited in a nonMendelian way. They do not pair with A chromosomes, and exhibite meiotic and mitotic instability and nondisjunction. At the same time they have little or no phenotypic effect on the host[1].

$\mathrm{B}$ chromosome DNA is quite identical to the corresponding sequence on the A chromosome complement[2-4]. Specific DNA sequences on the B chromosome have been an attractive research area on B chromosomes. So far a few B chromosome specific DNA sequences have been identified. D1100 is the first B chromosome specific sequence that had been isolated in plants[5]. It is located on the subtelomeric domain of rye B chromosomes. E3900

* Corresponding author: Prof. Rui Yang CHEN

Tel: 0086-022-23508241; Fax 0086-022-23497010;

E-mail: chenry@eyou.com

Received Jan-14-2002 Revised Feb-8-2002 Accepted Feb-18-2002 is another specific sequence discovered on rye B chromosome and is homologous to retrotransposons[6], [7]. In Brachycome dichromosomatia, Bd49, a B chromosome centromere specific DNA sequence, was found by subtractive hybridization[8],[9]. Several maize B centromere specific DNA sequences have been isolated as well[10]. Recent research showed that these sequences might originate from maize chromosome 4[11]. All of these specific sequences found in plants are highly repetitive and located on the centromeric or telomeric domains. Obviously, more B chromosome specific DNA sequences are required for describing the origin and the evolution of B chromosomes.

Various DNA fingerprinting techniques, such as restriction fragment length polymorphisms (RFLP), random amplified polymorphic DNA (RAPD), simple sequence repeat (SSR) and so on, have been developed. Amplification fragments length polymorphism (AFLP) technique developed by Vos et al[12] provides a number of appealing features in the fingerprinting of genomes of different complexity, including that of maize. The technique is based on the selective amplification of a subset of genomic restriction fragments using PCR. AFLP has been widely used to genetic and breeding study[13],[14]. So far 
reports using the AFLP technique to detect differences of genomes with and without B chromosomes are quite rare.

In this article we described the isolation and characterization of a B Chromosome specific DNA sequence, M8-2D, obtained from AFLP analysis of maize genomes with and without $\mathrm{B}$ chromosomes.

\section{MATERIALS AND METHODS}

Seeds of black Mexican sweet maize with B chromosomes B542A (+B) and without B chromosome B542B (0B) were obtained from Maize Genetic COOP Stock Center, Illinois, USA. They were cultured in sterile Linsmaier-Skoog (LS) media in the dark for about 15 days.

\section{Cytogenetic preparation}

Mitotic spreads for in situ hybridization were obtained from root tips according to Chen et al[15]. In brief, root tips was successively immersed in $4 \mathrm{mM}$ amiprophos-methyl (APM) for $2.5 \mathrm{~h}$ double distilled water for $30 \mathrm{~min}$, mixed with $2.5 \% \mathrm{w} / \mathrm{v}$ cellulase and pectinase for $1 \mathrm{~h}$, double distilled water for $20 \mathrm{~min}$ and Carnol 担 fixation (methanol: acetic acid $3: 1 \mathrm{v} / \mathrm{v}$ ). Finally, root tips were squashed on a slide and dried with hot air.

\section{Genomic DNA preparation}

The karyotypes of each seed were examined to ensure the existence of B chromosomes before the extraction of individual genomic DNA. Genomic DNA was isolated based on the procedure described by Murray et al[16]. Ten 0B individual genomic DNA and ten $+\mathrm{B}$ individual genomic DNA were mixed respectively for future AFLP analysis. DNA concentration was estimated in comparison with known concentration.

\section{AFLP analysis}

AFLP analysis was performed according to AFLP Analysis System Kit I protocol (Gibco BRL). 8 EcoRI selective primers (Eprimer) and $8 \mathrm{MspI}$ selective primers (M-primer), total 64 primer combinations were employed (Tab 1). Products of selective amplification were visualized by silver staining described by Bassam et al[17].

\section{AFLP markers (AFLPs) purification and cloning}

Drop $50 \mu \mathrm{l}$ TE buffer ( $10 \mathrm{~m} M$ Tris and $0.1 \mathrm{~m} M$ EDTA) on the surface of the dry polyacrylamide gel for a while. Cut the specific bands with a sterile knife and transfer the band into an eppendorf tube containing $30 \mu \mathrm{l} \mathrm{TE}$ buffer. Release DNA by heating the tube in a boiling water bath for $10 \mathrm{~min} .1 \mu \mathrm{l}$ of the supernate was enough for the DNA template of $20 \mu \mathrm{l}$ reaction solution. The amplification program and primers were the same as in the AFLP analysis. The PCR products were linked to pGEM-T vector (Promega) and transferred into E.coli DH 5 a .

\section{Southern hybridization}

Genomic DNA was digested with HaeIII (Hua Mei) at $37^{\circ} \mathrm{C}$ overnight. DNA fragments were resolved in $0.7 \%$ agarose gels in $0.5 \times$ TBE buffer $(1 \times$ means $89 \mathrm{mM}$ Tris, $89 \mathrm{mM}$ boric acid, $2 \mathrm{mM}$ EDTA, pH 8.0) without Ethidium Bromide (EB) to avoid background and subsequently transferred to Genescreen Plus membrane (NEN). For hybridization, DNA probes were labeled with DIG (digoxigenin-dUTP, Roche) by random-primed DNA synthesis. Hybridization was carried out overnight at $42^{\circ} \mathrm{C}$ in DIG Easy Hyb (Roche). Blots were washed successively in $2 \times$ SSC, 0 . $1 \% \mathrm{SDS}$ at room temperature $(1 \times \mathrm{SSC}$ is $0.15 \mathrm{M} \mathrm{NaCl}$ and 0.015 $\mathrm{M}$ sodium citrate); $0.5 \times \mathrm{SSC}, 0.1 \% \mathrm{SDS}$ at $68^{\circ} \mathrm{C}$ twice. The hybridization signal was detected by enzyme immunoassay with CSPD (Roche). The membrane was exposed to X-ray film to for appropriate $1 \sim 2 \mathrm{~min}$.

\section{Sequencing and sequence analysis}

Sequencing was done by Songon (Shanghai). Analysis of sequences similarity was performed with BioEdit sequence aligment editor[18] and Vector NTI suite 7.0 (Imformax).

\section{Fluorscence in situ hybridization (FISH)}

FISH was carried out as described in Nonradioactive In situ Hybridization Application Manual (Second Edition, Roche). Briefly, probe was labeled as southern hybridization. Hybridization buffer contained $50 \%$ deionized formamide, $2 \times \mathrm{SSC}, 50 \mathrm{mM}$ sodium phosphate (pH 7.0), $5 \%$ dextran sulfate, and $3 \mathrm{ng} / \mathrm{ml}$ probe. The buffer was denatured at $98^{\circ} \mathrm{C}$ for $10 \mathrm{~min}$ before used. Slides with metaphase spreads were treated with $70 \%$ deionized formamide in $2 \times \mathrm{SSC}$ at $68^{\circ} \mathrm{C}$ for 2 mins, then apply $15 \mu \mathrm{l}$ denatured hybridization buffer onto the slides, and incubate at $80{ }^{\circ} \mathrm{C}$ for $5 \mathrm{~min}$ and at $37^{\circ} \mathrm{C}$ overnight. The slides were washed with $2 \times \mathrm{SSC}, 30 \%$ deionized formamide at $37^{\circ} \mathrm{C}$ for $5 \mathrm{~min}$ and $2 \times \mathrm{SSC}$ at $37^{\circ} \mathrm{C}$ for $5 \mathrm{~min}$ twice. Signal was detected with Anti-DIG-fluorescent-conjugate. Metaphase spreads were counterstained with $10 \mathrm{ng} / \mathrm{ml}$ propidium iodle(PI). Epifluorescence signal was recorded by Kodak 1600 film.

\section{RESULT}

The pairs of selective primer combinations used are shown in Tab 1. About 2000 AFLPs had been detected and only $5+\mathrm{B}$ genome specific AFLPs were

Tab 1. Selective primers used for AFLP analysis

\begin{tabular}{ccccccccc}
\hline Selective Primer & \multicolumn{7}{c}{ 5' end selective bases } \\
\hline E-Primer & E-AAC & E-AAG & E-ACA & E-ACC & E-ACG & E-ACT & E-AGC & E-AGG \\
M-Primer & M-CAA & M-CAC & M-CAG & M-CAT & M-CTA & M-CTC & M-CTG & M-CTT \\
\hline
\end{tabular}


obtained from the combinations of E-ACC/M-CTC; E-AGG/M-CAA and E-AGG/M-CAC, named as M46U, M4-6D, M8-1 (Data not shown), M8-2U and M8-2D (Fig 1) respectively. The five AFLPs appeared consistently in the repeat AFLP analysis and the analysis with $5 \mathrm{~B}$ and $7 \mathrm{~B}$ individuals respectively. Later in our research, M4-6U and M4-6D was abandoned for its poor reproduction in amplification from AFLPs recovered products, while the other three markers were performed well (Fig 2). M8-1, M8-2U and M8-2D were then labeled as probes and hybridized to $0 \mathrm{~B}$ and $+\mathrm{B}$ genomic DNA digested by HaeIII.

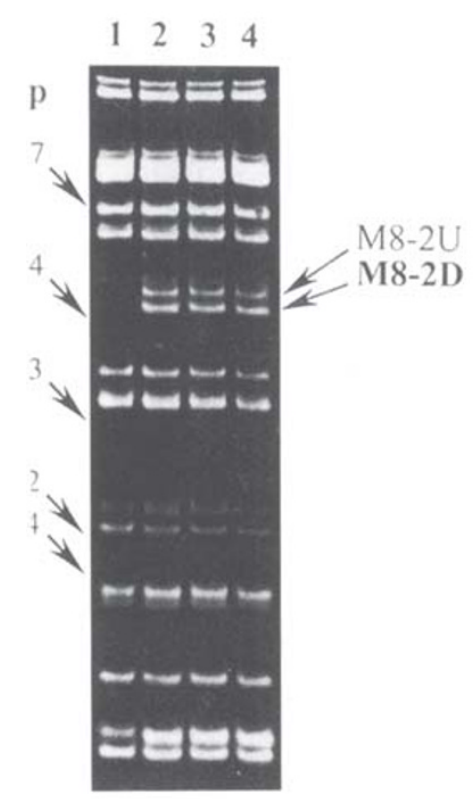

Fig 1. AFLP analysis in $0 \mathrm{~B}$ genome (Lane 1), +B genome (Lane 2). 5B individual genome (Lane 3 ) and 7B individual genome (Lane 4) using selective primers E-AGG/M-CAC.

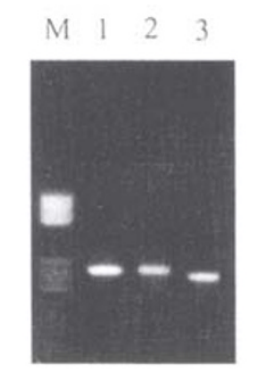

Fig 2. M8-1 (Lane 1), M8-2U (Lane 2) and M8-3D (Lane 3) were amplified steadily from the recovered products of corresponding bands. Lane M was a marker,pBR322/HaeIII.
Probe M8-1 and M8-2U produced same signals in $0 \mathrm{~B}$ and $+\mathrm{B}$ genomic DNA (data not shown). Probe M8-2D produced strong signal only in $+B$ genomic DNA, whereas very weak signal observed in $0 \mathrm{~B}$ genomic DNA only if prolonged the exposure time of X-ray film (Fig 3). The results of Southern hybridization indicated all of the three AFLPs were highly repetitious DNA sequences in maize genome, but only M8-2D was specific to maize B chromosome. If reducing the stringency of hybridization condition, more signal should be appeared in 0B genoic DNA.

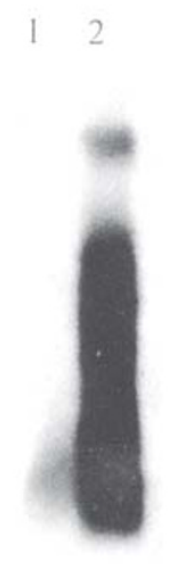

Fig 3. Labeled M8-2D was hybridized to $0 \mathrm{~B}$ genome (Lane 1 ) and + B genome (Lane 2)

The sequence of M8-2D was about 200bp long. Our GenBank database search illustrated that M8$2 \mathrm{D}$ is homologous to a series of corn B chromosome centromeric specific sequences (Genbank accession number: ZMU61991 ZMU62002 and S97586). All of these B chromosome specific sequences have similar sequence characters (Fig 4). The sequence of M8$2 \mathrm{D}$ also contains telomeric repeat unit AGGGTTT conserved in plants. It illustrated high homology to telomeric and subtelomeric repeat sequences of many plant species such as maize, Arabidopsis thaliana, wheat, rice and so on. Tandem repeat (AGGGTTT) $\mathrm{n}$ could be regarded as the ancestral sequence of M8$2 \mathrm{D}$ based on the comparison of them (Fig 5). In addition telomere repeats also were found in the other B chromosome specific sequences[10].

Although M8-2D is a B chromosome specific sequence, it shares low homologous with several clones (Genbank accession number AF334166 AF334180) from the centromeric domain of maize chromosome 4 in GenBank database. 

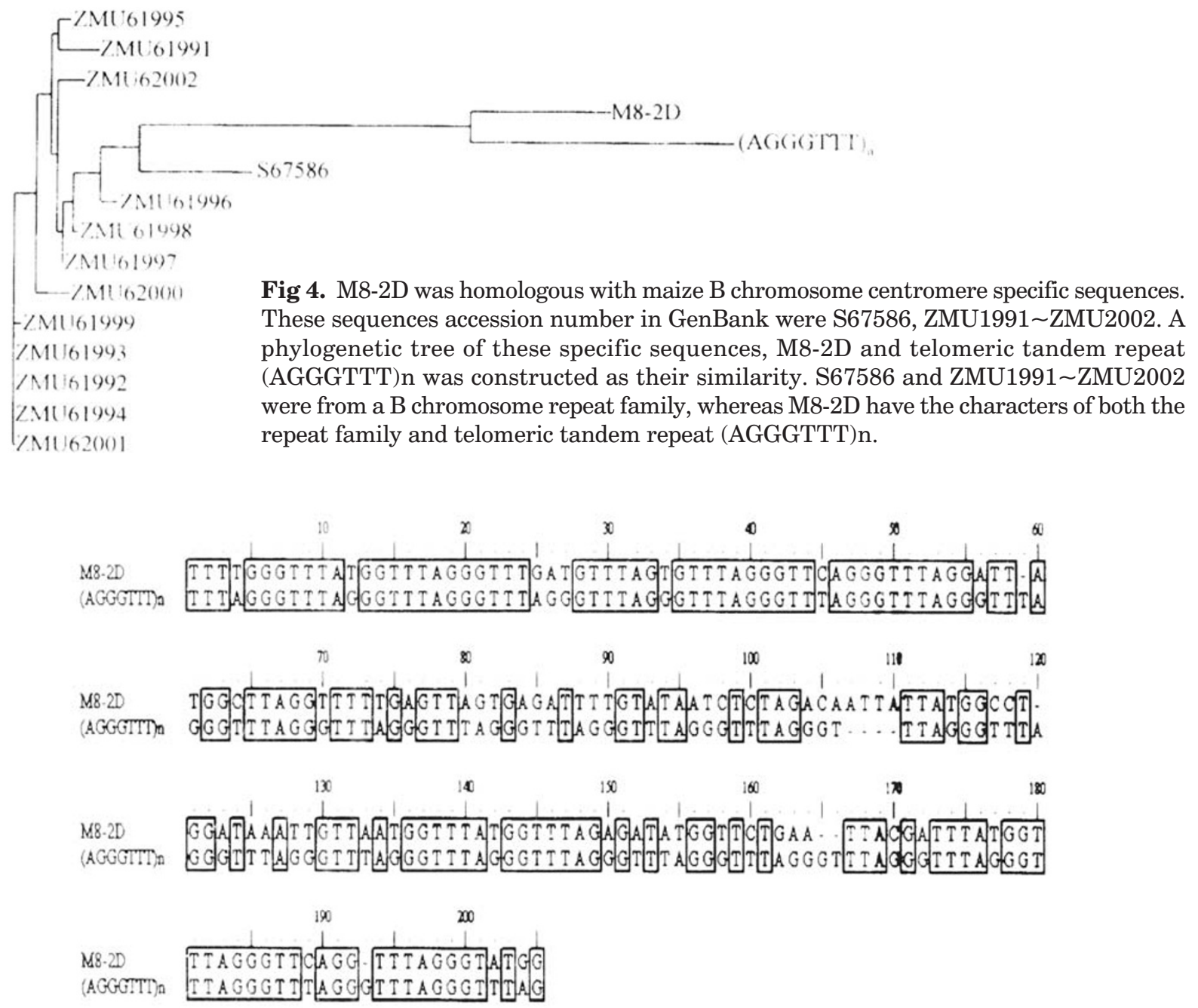

Fig 5. The sequence comparison between M8-2D and teleomeric tandem repeat (AGGGTTT)n. The sequences in rectangles were the same. There was high homology between them
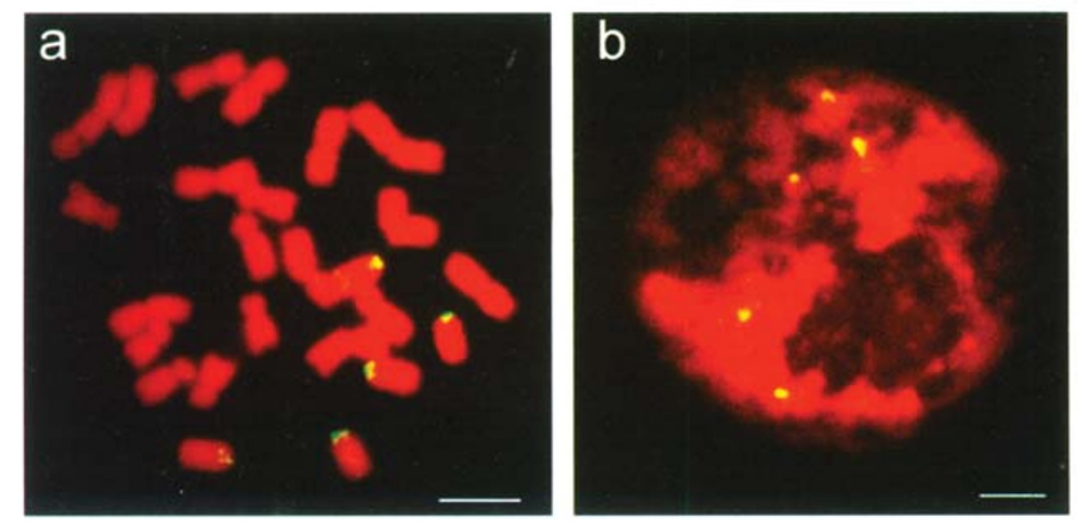

Fig 6. Metaphase cell of maize $(2 \mathrm{n}=20+5 \mathrm{~B})$ after propidium iodle $(\mathrm{PI})$ staining and fluorescence in situ hybridization (FISH) with labelled M8-2D. The centromeric region of each B chromosome show a strong hybridization in metaphase spread (a) and interphase nucleus(b). Bar meant $5 \mu \mathrm{m}$ long. 
The distribution of M8-2D on chromosome was also studied with FISH (Fig 6). The result clearly showed M8-2D was located mainly on centromeric domain of all B chromosomes. Weak signal could be observed on the B chromosome telomeric domain and the A chromosomes including chromosome 4. But the weak signal could not be seen in Fig 5 .

\section{DISCUSSION}

On the one hand, AFLPs were produced based on the double digestions of two restriction endonucleases, the length of selective base on the 3 ' end of selective primer and the combination of selective primers. So changing the endonuclease combination, for instance replacing EcoR I with PstI, or increasing the selective primer combinations would add more chances in searching B chromosome specific AFLPs. On the other hand, materials for AFLP analysis should have almost the same genetic background except the target character or genes. Otherwise many unrelated difference would be found. It would take lots of work to identify the true difference or polymorphism of our interest. In this paper, the genetic backgrounds of the maize B542A (+B) and B542B (0B) were so similar that only 5 markers were specific to $+\mathrm{B}$ genomes among near 2000 AFLPs.

AFLPs are somewhat like RFLPs in that new polymorphic markers were produced from the changes of restriction endonuclease recognition sequence. M8-1 and M8-2D were common sequences to $\mathrm{OB}$ and $+\mathrm{B}$ genomes revealed by Southern hybridization. But the two common sequences on B chromosomes had been changed at the Mse I or EcoR I cleavage site while not on the A chromosomes.

B chromosome specific DNA sequences were helpful not only for explaining B chromosome behavior but also for providing evidence of the origin and evolution of B chromosomes. M8-2D and other maize B chromosome specific DNA sequences[10] were all located on the centromeric region, but we still did not know what a role they played. So far, there is little of knowledge about plant centromeric DNA sequences. Sau3A9 exists in the centromeres of Gramineae species including B chromosomes[19]. $\mathrm{RCS} 2$ family present about 6000 times in the rice genome was detected only in Oryza species[20]. In GenBank database search, M8-2D was only homolo- gous to clones of maize chromosome 4 centromere. The result was similar to the previous research by Page et al[11]. They reported that centromeric sequences of maize chromosome 4 were hybridized to B chromosome specific sequences at reduced stringency of hybridization. The researchs suggested $\mathrm{B}$ chromosome centromere might come from degenerated centromere of maize chromosome 4 . But the further research was required to clarify the interesting question, how the B chromosome specific sequences affected chromosome paring in meiosis.

Telomeres are important molecular entities, required for accurate replication and stability of chromosomal ends. Telomeric sequence repeat (AGGGTTT)n in the telomere or subtelomere regions was conserved in plants as an important part of chromosomes. Meyne et al[21] reported the intrachromosomal distribution of non-telomeric sites of the telomeric repeat (AGGGTT)n in 100 vertebrate species. In about half of these species including fishes, birds, reptiles, amphibians and mammalians, non-telomeric block of the repeat was detected in the pericentric regions of chromosomes. Telomeric-like repeats have also been found at the centromeric regions in Arabidopsis thaliana[22] and tomato[23]. Our research also showed that telomeric repeat unit AGGGTTT existed in both centromeric regions and the telomeric regions of maize $B$ chromosomes.

The origin of these non-telomeric sites in the maize B chromosome and other species is an interesting puzzle. They might come either from fusion of chromosomes, or from amplification of stretches of tandem repeat[21],[24]. Regardless of the origin of non-telomeric block of telomeric repeat (AGGGTTT)n, they could be looked as the relic of chromosome rearrangements. These regions might act as latent telomeres that might play the role of telomere when new chromosome fragments were produced. In human cytogenetic research, crypticcentromeric regions have been found for years[25]. The region might act as centromere of new chromosome fragments. Although the common sequence of autonomously replicating sequence (ARS) was not been identified. There are more ARS than seem necessary in the genome replication[26]. Human artificial chromosome (HAC) was constructed successfully as the three functional elements were ar- 
ranged properly[27],[28]. Likewise, B chromosome could also be constructed by the latent or cryptic functional elements.

\section{ACKNOWLEDGEMENTS}

We expressed our appreciation for the heartful help of Dr. Jonathan S. Cook and Dr. Darren X. Ji in Procter and Gamble Pharmaceuticals, Inc., and James A. Birchler in Division of Biological Sciences, University of Missouri. This research was supported by grant from National Natural Sciences Foundation of China (39970357).

\section{REFERENCES}

[1] Jones RN, Rees HB chromosomes. Acdemic Press 1982:1167.

[2] Sandery MJ, Forster JW, Macadam SR, Blunden R, Jones $\mathrm{RN}$, Brown SDM. Isolation of a sequence common to Aand B-chromosomes of rye (Secale cereale) by microcloning. Plant Mol Bio Rep 1991; 9(1):21-30.

[3] Houben A, Leach CR, Verlin D, Rofe R, Timmis JN. A repetitive DNA sequence common to the different $\mathrm{B}$ chromosomes of the genus Brachycome. Chromosoma 1997; 106:513-9.

[4] Jamilena M, Garrido-Ramos M, Rej n CR, Rej n MR. Molecular relationship between the A and B chromosomes of Crepis capillaries. Heredity 1994; 73:527-31.

[5] Sandery MJ, Forster JW, Blunden R, Jones RN. Identification of a family of repeated sequences on the rye $\mathrm{B}$ chromosome. Genome 1990; 33:908-13.

[6] Blunden R, Wilkes TJ, Forster JW, Jimenez MM, Sandery MJ, Karp A, Jones RN. Identification of the E3900 family of rye B chromosome specific repeated sequences. Genome 1993; 36:706-11.

[7] Langdon T, Seago C, Jones RN, Ougham H, Thomas H, Forster JW, Jenkins G, De Novo evolution of satellite DNA on the rye B chromosome. Genetics 2000; 154:869-84.

[8] John UP, Leach CR, Timmis JN. A sequence specific to B chromosomes of Brachycome dichromosomatica. Genome 1991; 34:739-44.

[9] Leach CR, Donald TM, Franks TK, Spiniello SS, Hanrahan CF, Timmis JN. Organisation and origin of a B chromosome centromeric sequence from Brachycome dichromosomatica. Chromosoma 1995; 103:708-14.

[10] Alfenito MR, Birchler HW. Molecular characterization of a maize B chromosome centric sequence. Genetics 1993; 135:589-97.

[11] Page BT, Wanous MK, Birchler JA. Characterization of a maize chromosome 4 centromeric sequence: evidence for an evolutionary relationship with the B chromosome centromere. Genetics 2001; 159:291-302.

[12] Vos P, Hohgers R, Bleeker M, Reijans M, Van De Lee T, Hornes M, Frijters A, Pot J, Peleman J, Kuiper M, Zabeau M. AFLP: a new technique for DNA fingerprinting. Nucleic Acids Res 1995; 23:4404-14.
[13] Cervera MT, Gusmao J, Steenackers M, Peleman J, Storme V, Vanden BA, Van Montagu M, Boerjan W. Identification of AFLP molecular marker for resistance against Melampsora larici-populina in Populus. Theor Appl Gent 1996; 93:733-7.

[14] Hartl L, Seefelder S. Diversity of selected hop cultivars detected by fluorescent AFLPs. Theor Appl Gent 1998; 96:112-6.

[15] Chen RY, Song WQ, Li XL, An ZP. A new method of plant mitosis chromosome spread. Acta Bota Sinica 1979; 21 : 297-8

[16] Murray MG, Thompson WF. Rapid isolation of high weight plant DNA. Nucleic Acids Res 1980; 8:4231-5.

[17] Bassam BJ, Caetano-Anoll G, Gresshoff GM. Fast and sensitive silver staining of DNA in polyacrylamide gels. Anal Biochem 1991; 196:80-3.

[18] Hall TA. BioEdit: a user-friendly biological sequence alignment editor and analysis program for Windows 95/ 98/NT. Nucl Acids Symp Ser 1999; 41:95-8.

[19] Jiang JM, Nasuda S, Dong FG, Scherrer CW, Woo SS, Wing RA, Gill BS, Ward DC. A conserved repetitive DNA element located in the centromeres of cereal chromosomes. Proc Natl Acad Sci USA 1998; 93:142103.

[20] Dong F, Miller JT, Jackson SA, Wang GL, Ronald PC, Jiang J. Rice (Oryza sativa) centromeric regions consist of complex DNA. Proc Natl Acad Sci USA 1998; 95:813540.

[21] Meyne J, Baker RJ, Hobart HH, Hsu TC, Ryder OA, Ward OG, Wiley JE, Wurster-Hill DH, Yates TL, Moyzis RK. Distribution of non-telomeric sites of the (TTAGGG) $\mathrm{n}$ telomeric sequence in vertebrate chromosomes. Chromosoma(Berl.) 1990; 99:3-10.

[22] Richards EJ, Goodman HM, Ausubel FM. The centromere region of Arabidopsis thaliana chromosome 1 contains telomere-similar sequence. Nucleic Acids Res 1991; 19: 3351-7.

[23] Presting GG, Frary KP, Tanksley SD. Telomere-homologous sequence occur near the centromeres of many tomato chromosomes. Mol Gen Genet 1996; 251:526-31.

[24] Slijepcevic P Telomeres and mechanisms of Robertsonian fusion. Chromosoma 1998; 107:136-40.

[25] Sacchi N, Magnani I, Fuhrman-Conti AM, Monard SP, Darfler M. A stable marker chromosome with a cryptic centromere: evidence for centromeric sequences associated with an inverted duplication. Cytogenet Cell Genet 1996; 73:123-9.

[26] Gilbert DM. Making Sense of Eukaryotic DNA Replication Origins. Science 2001; 294:96-100.

[27] Harrington JJ, Van Bokkelen G, Mays RW, Gustashaw K, Willard HF. Formation of de novo centromeres and construction of first-generation human artificial microchromosomes. Nat Genet 1997; 15:345-55.

[28] Henning KA, Novotny EA, Compton ST, Guan XY, Liu PP, Ashlock MA. Human artificial chromosomes generated by modification of a yeast artificial chromosome containing both human alpha satellite and single-copy DNA sequences. Proc Natl Acad Sci USA 1999; 96:592-7. 